\title{
Risk Analysis Model with Interval Type-2 Fuzzy FMEA - Case Study of Railway Infrastructure Projects in the Republic of Serbia
}

\section{Dragana Macura ${ }^{1}$, Milica Laketić ${ }^{1}$, Dragan Pamučar ${ }^{2}$, Dragan Marinković ${ }^{3,4}$}

${ }^{1}$ University of Belgrade, Faculty of Transport and Traffic Engineering

Vojvode Stepe 305, 11000 Belgrade, Serbia

d.macura@sf.bg.ac.rs, m.laketic@sf.bg.ac.rs

${ }^{2}$ University of Defence in Belgrade, Department of Logistics

Pavla Jurisica Sturma 33, 11000 Belgrade, Serbia

dragan.pamucar@va.mod.gov.rs

${ }^{3}$ University of Nis, Faculty of Mechanical Engineering

A. Medvedeva 14, 18000 Nis, Serbia

${ }^{4}$ Technische Universität Berlin, Department of Structural Mechanics and Analysis, Strasse des 17. Juni 135, 10623 Berlin, Germany

dragan.marinkovic@tu-berlin.de

Abstract: Considering the impact of risk events to costs, time and quality of infrastructure projects, it is necessary to invest in risk management in order to prevent or mitigate negative consequences. Risk analysis should monitor the project through the whole project life cycle: from the planning through execution and controlling to finishing. In this paper, we have used Interval Type-2 Fuzzy Logic based Failure Mode and Effects Analysis (FMEA) to get a better insight into the risk events that occur in the railway infrastructure projects. The study's main contribution is developing and implementing a comprehensive and robust framework for defining and handling with the most important risk events regarding the railway infrastructure projects. The Interval Type-2 Fuzzy Logic is used to tackle the uncertainty in risk assessment. In order to illustrate the validity and capability of the model, the presented approach has been applied to the railway infrastructure projects in the Republic of Serbia. Each risk event has been analyzed through severity, occurrence and detection. The events were ranked based on the Fuzzy Risk Priority Number (RPN). This research also proposes strategies for the most important events in terms of risk.

Keywords: Risk analysis; Railway infrastructure project; FMEA; Fuzzy logic; Interval Type2 Fuzzy Sets 


\section{Introduction}

The economic and social development of a country depends on the enlargement of the transport infrastructure, so the investment in the infrastructure development and maintenance is mandatory for the faster economic growth of a country. Risk management should play a key role in planning, project execution and later controlling the performed infrastructure project. It should be present throughout the whole life of the project and that is what makes the difference compared to the former realization of the project. Exceeding estimated costs, delays in construction deadlines, poor cooperation between management and contractors are just some of the events that can increase costs. The construction of large transport infrastructure projects in the past has recorded large budget overruns. Dealing with the risks and uncertainties are unavoidable challenge of every infrastructure project managers.

Some risks cannot be completely eliminated, but it is necessary to identify them effectively and in a timely manner in order to make a plan to mitigate their impacts. Risk management raises the awareness of management, elevate the probability of success in achieving goals, serves to exchange views within the organization, reduces surprises, increases self-confidence when making difficult decisions, provides higher quality services and protects the organization's reputation.

An infrastructure project is most often defined as a complex technicaltechnological, economic, financial and legal process consisting of a set of coordinated and controlled activities with the aim of implementing the project successfully to completion. Each project has its own estimated time to be completed. Of course, shifts in infrastructure projects are usually inevitable, but even in these time shifts there must be a limit. What most often leads to exceeding the scheduled deadlines for construction or modernization is considered as risk.

Literature often defines risk as uncertainty that can positively or negatively affect the project realization. Risk management allows the investor to anticipate potential negative outcomes that may occur during the project execution. Delays of project realization are often inevitable, but a risk management plan is used to predict them.

The risk management process, based on EU projects, consists of the following steps:

- $\quad$ risk identification and description;

- $\quad$ risk assessment;

- $\quad$ risk management (risk response);

- monitoring and reporting on risks.

The first step in the risk management process is to identify potential risks. Some of the methods for identifying risks are: checklists, use of data from the previous period, stakeholder consultations, comparison with similar organizations, etc. The description of the risk facilitates definition of measures for its reduction. 
The risk assessment, which refers to predicting the probability of the occurrence on an unwanted event and the impact of the risk, was performed by experts. The impact of risk is based on an assessment of the effect that a negative event would have on the design of the project. The remaining two steps are performed by risk management in the organization itself.

It is desirable that the risk assessment be performed objectively in order to obtain as reliable data as possible. The more the risks are talked about and the more they are studied there are less chance of surprises.

This paper discusses railway infrastructure projects, from the aspect of risks that may occur during the construction, modernization and reconstruction of the railway infrastructure. The group decision - making was included in the model presented in this paper. Based on railway experts' opinions, expressed through a survey, the values of probability of occurrence, severity and detection of risks that are most often present on railway infrastructure projects in the Republic of Serbia were obtained. The survey respondents were the railway experts who work at: University of Belgrade, Faculty of Transport and Traffic Engineering (FTTE); Ministry of Construction, Transportation and Infrastructure of the Republic of Serbia (MoCTI); and Infrastructure of Serbian Railway JSC (ISR). Six experts were from the first two institutions and two were from ISR. Their answers have different weights according to their work experience, i.e., their years of service, and description of job. A higher weight has an expert working on the railway infrastructure projects. This has been done by WGMM (Weighted Geometric Mean Method).

Given that the extension of deadlines for the completion of construction or modernization of railway infrastructure is a frequent event, this study provides a better insight into the risks involved and indicates causes of delays in the implementation of infrastructure projects. Which risks are the most relevant, the most often and with high severity in the Republic of Serbia - was researched in this study. This has been done by FMEA. Afterwards, the Interval Type-2 Fuzzy logic system (IT2-FLS) was developed in order to help managers or decision makers in assessment of the risk event. The IT2-FLS model has an ability to present the realworld projects and tackle the uncertainty.

The aim of the developed model is to define the most important risks by subjective judgments of experts on the probability and impact under IT2-FLS FMEA. The advantages of the proposed model are: reducing the individual subjective preferences with multi-group decision making process, solving the real-world issue and handling the uncertainty with the Interval Type-2 Fuzzy logic.

This paper is organized as follows. After the Introduction, there is a brief review of the relevant literature related to the Type-2 Fuzzy Logic and FMEA applications. Then, Section 3 gives a description of the methodology applied for. The results of the proposed model are presented in Section 4. The last in the series is the conclusion, as Section 5. 


\section{Brief Literature Review}

In risk detection of infrastructure projects, FMEA is considered one of the most used tool. FMEA in cooperation with Fuzzy Logic presents the reliable way of calculating risk from aeronautical to transportation projects. In the literature review process, the papers highlighted below use the FMEA and Fuzzy Logic to assess the risk of railway projects.

Panja et al. [1] dealt with the failure analysis of Indian railway signaling systems through fuzzy Risk Priority Number (RPN) and FMEA. Twenty five rules out of one hundred have been generated and taken as serious in risk assessment. Zhu et al. [2] introduced effective strategy for analyzing and diagnose urban rail transit vehicle maintenance. Fuzzy-set based assessment for FMEA as a quantitative tool is proposed for Shanghai URT System. Ghodrati et al. [3] showed integration of fuzzy RPN and Analytical Hierarchy Process (AHP) as a method for reducing uncertainties and ambiguities. The research topic is maintenance of rolling stocks. Huang and Zhang [4] described an approach which combines FMEA and pessimistic - optimistic fuzzy information, considering Acceptable Risk Coefficient (ARC) on an example of railway dangerous goods transportation. That approach presents system problems as ranking risks based on the level of severity. Tong et al. [5] used FMEA and fuzzy multiple attribute decision making theory to evaluate risk of the full life cycle of the Maglev train system. Sarkar and Singh [6] presented two combined approaches Fuzzy Expected Value Method (FEVM) and Fuzzy Failure Mode and Effects Analysis (FFMEA) for a complex infrastructure project for the metro rail in India. The authors used interactions with experts through questionnaire survey to identify major risks. Tafazzoli [7] experimented with the crisps value of fuzzy FMEA to identified and mitigate potential causes of delay in each infrastructure project through their priority. Priority level is determined on the basis of survey and expert opinions.

Type-2 Fuzzy logic is suitable for the risk analysis in projects, when there are a lot of imprecisions and uncertainty of data. There are recently published papers dealing with the prioritization and evaluation of the decisions and initiatives with Interval Type-2 Fuzzy Logic and other methods that could be easily implemented for the risk analysis regarding the transport projects, such as: COPRAS [8], Simulated Annealing [9], Interval Agreement Approach [10], Additive Ratio Assessment [11], MABAC [12]. In the literature review process, those papers that operate with Type2 Fuzzy logic in order to achieve the highest quality assessments within the project risk management are highlighted. Most of these papers use some additional analysis to obtain reliable data.

Seyed et al. [13] provide a better insight into the application of an interval Type-2 Fuzzy risk analysis model (IT2FRAM) in order to determine the contingency reserve in construction projects. IT2FRAM is defined as an extension of a fuzzy arithmetic-based risk analysis method which deals with uncertainties through consideration of the opinions of several subject matter experts in a way to develop 
the membership functions of linguistic terms. It's explained how Type-2 Fuzzy logic can aggregate non-linear membership functions into trapezoidal. Fu et al. [14] described an approach which combines Type-2 Fuzzy logic and Multi-Criteria Optimization and Compromise Solution (VIKOR) method for operational risk assessment of railway train. This combination can be used to rank the risk of any system components considering calculated uncertainty, expert opinions and qualitative and quantitative information about the system. The authors showed the difference between static risk assessment and proposed approach through the effectiveness and feasibility. Kilic and Kaya [15] used Type-2 Fuzzy sets as helping tool for decision make in a prioritization of provinces for public grants allocation process. Crisp sets and Type-2 Fuzzy sets have been used in Multi-Criteria Decision Making (MCDM) process to illustrate better model. It also helps with creating correct strategies for socio-economic development. Yong et al. [16] deals with risk assessment of metro station with combination of Type-2 Fuzzy set and Technique for Order Preference by Similarity to Ideal Solution (TOPSIS) method. Listed methods considered: people, equipment, management and accidents factors in the same time. Obtained results reflect actual and objective risk status of metro station which can provide needed support for decision makers. Pestana et al. [17] introduced enhanced singleton Type-2 Fuzzy logic for detection of possible faults that can occur in a switch machine in railway system. The simulations are performed with real data set, and the results are compared with other models mentioned in the literature. Three main reasons for risky events are investigated and a complete model is created based on them. Kumar and Mohamed [18] presented two fuzzy models for solving transportation problems which occur due to nature of transport. Using Type-2 or Type-4 Fuzzy logic the decision maker can easier set the boundaries of acceptance for the transportation cost or profit. In order to use crisp data, Maity and Kumar [19] experimented with Type-2 Fuzzy sets and trapezoidal fuzzy numbers (TFNs). As previous paperwork, this also refers on solving transportation problem. Using this approach, the complexity of computation is reduced significantly compared to the Type-1 Fuzzy sets. Kundu et al. [20] worked on resolving multi-solid transportation problem with Type-2 triangular Fuzzy logic. Variables like transportation costs, supplies and demands are considered fuzzy variables. Deterministic problems, which occur after the calculation, are obtained by applying LINGO solver and the genetic algorithm. Soner et al. [21] suggested application of Analytic Hierarchy Process (AHP) and VIKOR methods under Type2 Fuzzy environment in maritime transportation. AHP and VIKOR help with solving multi-attribute decision making problems, and fuzzy logic deals with uncertainties that happen during linguistics assessment of decision makers. A demonstration of proposed approach was done to show its importance in protecting cargo from external unwanted events. Another example of application interval Type-2 Fuzzy logic in transportation is showed by Deveci et al. [22] where they use Weighted Aggregated Sum Product Assessment (WASPAS), TOPSIS and Type-2 Fuzzy MCDM model to select a car sharing station. Type-2 Fuzzy sets provide a better risk insight in process of describing membership functions and non- 
membership functions. Deveci et al. [23] have worked on service quality improvement of domestic airlines on Istanbul - London route. As in previous cases, Type-2 Fuzzy sets are used in order to obtain as reliable data as possible for improving the service quality.

To the best of our knowledge, the integration of Interval Type-2 Fuzzy logic and FMEA methods have not been used for the railway projects evaluation. The IT2FLS FMEA model proposed in this study is a novel, structured, and systematic framework used to close this gap in the literature and practice. The developed model was used to evaluate priority of risks in rail infrastructure.

\section{Developed IT2-FLS FMEA Model}

\subsection{Input Data}

A survey was used in order to define the most relevant risk events for the considered case study. It was filled by experts in the field of railway transport: infrastructure, educational institutions and relevant authorities in the Republic of Serbia. The questionnaire included 26 risk events that occur during the construction or modernization of railway infrastructure projects. Potential risks (Table 1) have been utilized from previous projects dealing with similar topics [7].

Determining the most relevant risk events in our survey was done by applying the multi-group decision making process. There were 9 respondents - railway experts from FTTE, MoCTI and ISR. The importance of the decision maker is integrated into the assessment process using the WGMM method. WGMM is one of the basic methods used in group decision making. The calculation formula is [29, 30]:

$W_{i}^{G}=\prod_{k=1}^{r}\left(\omega_{i k}\right)^{\beta_{k}}, i \in\{1,2, \ldots, n\}$

where $r$ is the number of decision makers, $k$ the decision maker' index $(1 \leq k \leq r)$, $\beta_{k}$ the weighting factor/importance of the $k$-th decision maker $\left(\beta_{k} \geq 0\right)$ [31-34]:

$\sum_{k=1}^{r} \beta_{k}=1$

Table 1

List of potential risk events

\begin{tabular}{|c|c|c|c|}
\hline 1. & Errors in contract documents & 14. & $\begin{array}{l}\text { Excessive change orders by the } \\
\text { owner during construction }\end{array}$ \\
\hline 2. & $\begin{array}{l}\text { Delay in approving project } \\
\text { documentation }\end{array}$ & 15. & $\begin{array}{l}\text { Excessive change orders by the } \\
\text { infrastructure management during } \\
\text { construction }\end{array}$ \\
\hline 3. & $\begin{array}{l}\text { Delays in providing the design } \\
\text { documents }\end{array}$ & 16. & $\begin{array}{l}\text { Time consuming decision making } \\
\text { process of the owner }\end{array}$ \\
\hline
\end{tabular}




\begin{tabular}{|c|c|c|c|}
\hline 4. & $\begin{array}{l}\text { Unrealistic schedule (bid duration is } \\
\text { too short) }\end{array}$ & 17. & $\begin{array}{l}\text { Unnecessary interference by the } \\
\text { owner }\end{array}$ \\
\hline 5. & $\begin{array}{l}\text { Ineffective delay penalties } \\
\text { provisions in contract }\end{array}$ & 18. & $\begin{array}{l}\text { Poor communication and } \\
\text { coordination of the owner with } \\
\text { designer and/or contractor }\end{array}$ \\
\hline 6. & $\begin{array}{l}\text { Selecting inappropriate project } \\
\text { delivery method }\end{array}$ & 19. & Inadequate contractor's experience \\
\hline 7. & $\begin{array}{c}\text { Complexities and ambiguities of } \\
\text { project design }\end{array}$ & 20. & Design errors \\
\hline 8. & $\begin{array}{c}\text { Inadequate experience of the } \\
\text { designer }\end{array}$ & 21. & $\begin{array}{l}\text { Misunderstanding between owner } \\
\text { and designer about scope of the } \\
\text { work }\end{array}$ \\
\hline 9. & $\begin{array}{l}\text { Inadequate site assessment by the } \\
\text { designer during design phase }\end{array}$ & 22. & Delayed payments by the owner \\
\hline 10. & $\begin{array}{l}\text { Delay to furnish and deliver the site } \\
\text { to the contractor }\end{array}$ & 23. & $\begin{array}{c}\text { Financial difficulties and } \\
\text { mismanagement by the contractor }\end{array}$ \\
\hline 11. & $\begin{array}{l}\text { Lack of contractor staff on the } \\
\text { project }\end{array}$ & 24. & $\begin{array}{l}\text { Financial difficulties with the } \\
\text { designer }\end{array}$ \\
\hline 12. & Inappropriate construction methods & 25. & $\begin{array}{c}\text { Poor site management and Quality } \\
\text { Control (QC) by the contractor }\end{array}$ \\
\hline 13. & $\begin{array}{l}\text { Contractor inefficiency (in } \\
\text { providing the labor, equipment and } \\
\text { handling subcontractors) }\end{array}$ & 26. & $\begin{array}{l}\text { Legal disputes between designer } \\
\text { and the owner }\end{array}$ \\
\hline
\end{tabular}

Based on years of experience and field of work, each experts is given importance as presented in Table 2:

Table 2

Values of importance factor $\left(\beta_{k}\right)$

\begin{tabular}{|c|c|c|c|c|c|c|c|c|}
\hline $\begin{array}{c}\text { Place of } \\
\text { employment }\end{array}$ & FTTE & FTTE & FTTE & ISR & MoCTI & MoCTI & MoCTI & ISR \\
\hline $\begin{array}{c}\text { Years of } \\
\text { work }\end{array}$ & - & 20 & 10 & - & 2 & - & 5 & 14 \\
\hline $\begin{array}{c}\beta_{k}- \\
\text { importance } \\
\text { factor }\end{array}$ & 0.1 & 0.12 & 0.12 & 0.15 & 0.11 & 0.11 & 0.11 & 0.18 \\
\hline
\end{tabular}

\subsection{FMEA Method}

Failure Mode and Effects Analysis is a method for identifying risks and effects that occur during project implementation. This method was developed in the mid 1960s in the United States for the needs of the Apollo mission as a risk control tool. After that, it found application in various industries and systems. The idea of the FMEA is to highlight the weaknesses of the system through compiling a list of priorities. 
The list is compiled based on the Risk Priority Number (RPN), and it is obtained by multiplying the following elements:

- $\quad$ Severity (S) - refers to impact of occurred risk on project realization;

- Occurrence $(\mathrm{O})$ - represent the probability of realization of risk event;

- Detection (D) - likelihood of detecting a risk event.

The respondents rated each risk event (Table 1) based on its occurrence, severity, and detection. Assessment of probability of occurrence, severity, and detection was performed on a scale of 1 to 5 , where 1 represents the absence of a risky event and 5 is a higher risk event.

After the survey was finished, six critical events with the most critical grades were highlighted (Table 3). The respondents assessed these events with the highest Relative Importance Index (RII) number. According to the RII number, events can also be sorted. The calculations of RII are presented in [7].

Table 3

The most important events and their RII number

\begin{tabular}{|l|c|}
\hline \multicolumn{1}{|c|}{ The main causes of construction delay } & RII $^{*}$ \\
\hline Poor site management and Quality Control (QC) by the contractor & 0.725 \\
\hline $\begin{array}{l}\text { Poor communication and coordination of the owner with designer } \\
\text { and/or contractor }\end{array}$ & 0.700 \\
\hline Lack of contractor staff on the project & 0.700 \\
\hline Delay in approving project documentation & 0.675 \\
\hline Ineffective delay penalties provisions in contract & 0.675 \\
\hline Time consuming decision-making process of the owner & 0.675 \\
\hline
\end{tabular}

\subsection{Interval Type-2 Fuzzy FMEA Approach}

Fuzzy Logic, introduced by Zadeh in 1965 [24, 25], is used when there is a lack of information or knowledge for presenting the values of real-world parameters. In 1975 the Type-2 Fuzzy Sets was introduced by Zadeh as well, as an extension of Type-1 Fuzzy Sets. The Interval Type-2 Fuzzy Sets are used when there is uncertainty about the membership functions. The differences between Type-1 (left image) and Type-2 (right image) Fuzzy Sets are presented at the Figure 1, where it can be seen that the membership functions are fuzzy values in Type-2 Fuzzy Logic [35-37].

The introduction of fuzzy logic in FMEA is done because it allows the usage of data that are uncertain or vague. Many events have more than simple true or false values, so in that case fuzzy FMEA is the best choice for sensitive results. 

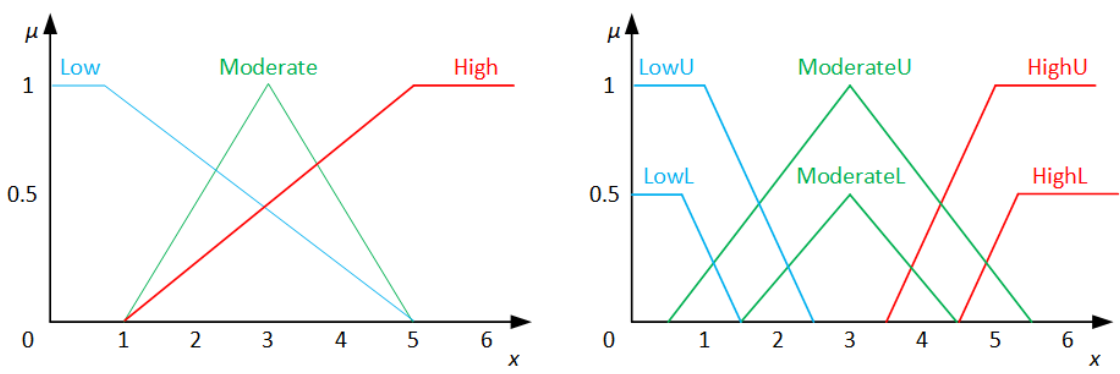

Figure 1

Type-1 and Type-2 Fuzzy Sets

Table 4 gives the quantitative description of main elements of the FMEA analysis.

Table 4

Quantitave description of severity, occurrence and detection

\begin{tabular}{|c|c|c|c|}
\hline $\begin{array}{c}\text { Level of risk (a higher number } \\
\text { indicates a higher risk) }\end{array}$ & Severity & Occurrence & Detection \\
\hline$\sim 1$ & Very low & $\begin{array}{c}\text { Very low } \\
\text { (Highly unlikely) }\end{array}$ & Very high \\
\hline$\sim 2$ & Low & $\begin{array}{c}\text { Low } \\
\text { (Unlikely) }\end{array}$ & High \\
\hline$\sim 3$ & Moderate & $\begin{array}{c}\text { Moderate } \\
\text { (It may occur) }\end{array}$ & Moderate \\
\hline$\sim 4$ & High & $\begin{array}{c}\text { High } \\
\text { (It is expected to occur) }\end{array}$ & Low \\
\hline$\sim 5$ & Very high & $\begin{array}{c}\text { Very high } \\
\text { (It will occur certainly) }\end{array}$ & Very low \\
\hline
\end{tabular}

The Interval Type-2 Fuzzy model was developed using the Matlab software (Figure 1). Fuzzy rules (If - Than rules) are defined on the basis of which the system from the combination of inputs determine the appropriate output.

The proposed Interval Type-2 Fuzzy FMEA model has three inputs: Severity, Occurrence and Detection [38,39]. Values for occurrence, severity, and detection were obtained through the survey, and these values are used as input for Interval Type-2 Fuzzy FMEA analysis.

The output value is fuzzy RPN and it was obtained by calculating the previous three inputs through Matlab-Simulink and represents the importance of the event in terms of risk. The output is in crisp form due to defuzzification.

Since all three input values are obtained using expert opinions. The domain for the severity, occurrence and detection are presented in the Table 5. 


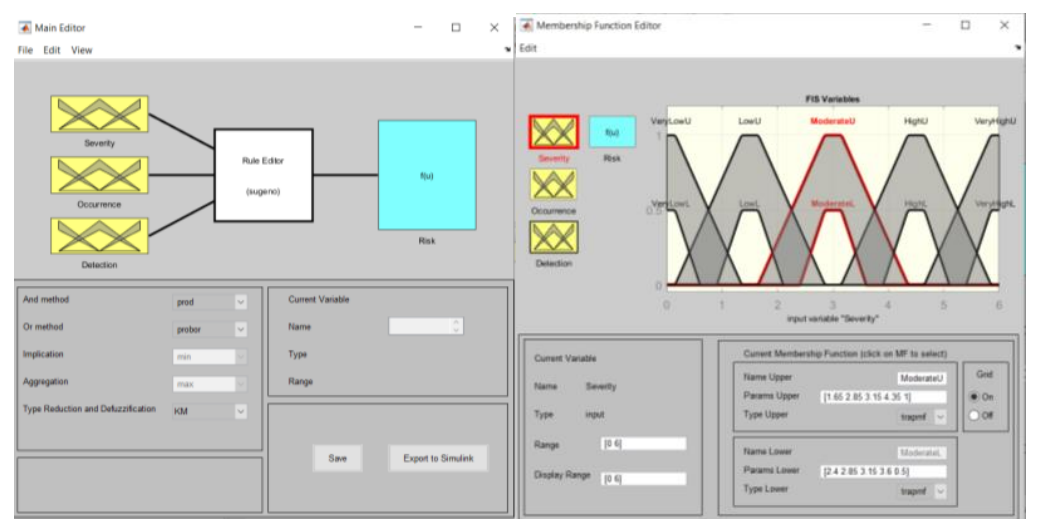

Figure 2

Developed IT2-FLS model in Matlab

Table 5

Trapezoidal Interval Type-2 Fuzzy Sets

\begin{tabular}{|c|c|c|}
\hline & Upper & Lower \\
\hline Very low & {$\left[\begin{array}{llllll}-1.35 & -0.15 & 0.15 & 1.35 & 1\end{array}\right]$} & {$\left[\begin{array}{llllll}-0.6 & -0.15 & 0.15 & 0.6 & 0.5\end{array}\right]$} \\
\hline Low & {$\left[\begin{array}{llllll}0.15 & 1.35 & 1.65 & 2.85 & 1\end{array}\right]$} & {$\left[\begin{array}{llllll}0.9 & 1.35 & 1.65 & 2.1 & 0.5\end{array}\right]$} \\
\hline Moderate & {$\left[\begin{array}{lllll}1.65 & 2.85 & 3.15 & 4.35 & 1\end{array}\right]$} & {$\left[\begin{array}{lllll}2.4 & 2.85 & 3.15 & 3.6 & 0.5\end{array}\right]$} \\
\hline High & {$\left[\begin{array}{llllll}3.15 & 4.35 & 4.65 & 5.85 & 1\end{array}\right]$} & {$\left[\begin{array}{lllll}3.9 & 4.35 & 4.65 & 5.1 & 0.5\end{array}\right]$} \\
\hline Very high & {$\left[\begin{array}{lllll}4.65 & 5.85 & 6.15 & 7.35 & 1\end{array}\right]$} & {$\left[\begin{array}{lllll}5.4 & 5.85 & 6.15 & 6.6 & 0.5\end{array}\right]$} \\
\hline
\end{tabular}

Here:

- Very low, Low, Moderate, High or Very high severity presents a very low, low, moderate, high or very high impact of risk event, respectively. The goal: The smaller severity is preferred.

- Very low, Low, Moderate, High or Very high occurrence presents a very low, low, moderate, high or very high chance of risk event occurrence, respectively. The goal: The smaller chance of occurrence is preferred.

- Very low, Low, Moderate, High or Very high detection presents a very low, low, moderate, high or very high chance that the risk will be detected in time, respectively. The goal: The higher chance of timely detection is preferred.

After creating the domain, the next step in conducting fuzzy FMEA analysis is to create fuzzy rules. Fuzzy rules in this case are performed based on numerical data from survey. An example of creating a rule is shown below:

Rule 1: IF the Severity is Very low and the Occurrence is Very low and the Detection is Very high, THEN the fuzzy RPN number is Very low. 
Rule 2: IF the Severity is Very low and the Occurrence is Very low and the Detection is High, THEN the fuzzy RPN number is Very low.

Rule 125: IF the Severity is Very high and the Occurrence is Very high and the Detection is Very Low, THEN the fuzzy RPN number is High.

Once the rules are generated, it is possible to start with the calculations as a way of obtaining risk criticality. The results of calculations show the riskiness of each of the potential causes of delay. At the end, it is possible to rank the risks and notice the impact they can have on the realization of infrastructure project.

Table 6

Calculation of fuzzy RPN

\begin{tabular}{|l|c|c|c|c|}
\hline \multicolumn{1}{|c|}{ Risk event } & Severity & Occurrence & Detection & RPN \\
\hline $\begin{array}{l}\text { Poor site management and Quality Control } \\
\text { (QC) by the contractor. }\end{array}$ & $\sim 5$ & $\sim 4$ & $\sim 4$ & 4.1 \\
\hline $\begin{array}{l}\text { Poor communication and coordination of } \\
\text { the owner with designer and/or contractor. }\end{array}$ & $\sim 4$ & $\sim 3$ & $\sim 5$ & 3.97 \\
\hline Lack of contractor staff on the project. & $\sim 3$ & $\sim 4$ & $\sim 3$ & 3.3 \\
\hline Delay in approving project documentation. & $\sim 3$ & $\sim 3$ & $\sim 4$ & 3 \\
\hline $\begin{array}{l}\text { Ineffective delay penalties provisions in } \\
\text { contract. }\end{array}$ & $\sim 2$ & $\sim 4$ & $\sim 3$ & 3 \\
\hline $\begin{array}{l}\text { Time consuming decision-making process } \\
\text { of the owner. }\end{array}$ & $\sim 3$ & $\sim 3$ & $\sim 2$ & 3 \\
\hline
\end{tabular}

\section{Results}

The fuzzy RPN number, that is calculated in Matlab, provide us an assessment of riskiness of each of potential causes. The list offer essential information about risk events by which it is possible to determine corrective measures. Failure modes having a higher RPN number are considered more significant than those with a lower RPN.

As we can see, high RII number is followed by high fuzzy RPN number. The first three risk events have the highest fuzzy RPN number, the remaining three have a value of 3 which is considered a moderate risk. By calculation of severity, occurrence and detection using fuzzy logic for 'Poor site management and QC by the contractor' we have got a very high risk $(\mathrm{RPN}=4.1)$ and it has to be considered a priority. Next one is 'Poor communication and coordination of the owner with designer and/or contractor' and it have RPN value of 3.97. This risk is also considered as high. The third risk event has an RPN value of 3.3 and a RII of 36 . The drastic drop in RII numbers is reflected in the estimation of RPN values. 
The third event has twice the value of the RII number than the first one and thus a much lower RPN value. All listed risks have observational importance but their RPN number shows what measures must be taken to prevent major consequences. The fuzzy model created to examine these events can also be used when estimating some other events related to railway infrastructure. It is also possible to reassess risk events after reduce measures have been taken.

The manner of dealing with risks is defined as actions (response) that are carried out in order to prevent the occurrence of risk, reduce the impact during the realization of risk or accept the consequences. In the world of risk management, there are four possible responses to risk:

- Risk avoidance - is used in project management if there is a situation where the cost-benefit ratio of the project is compromised and the risk can be reduced to zero by some changes.

- Risk mitigation - is based on the fact that the risk activity will continue, but the controls will be carried out regularly to minimize the possible risk.

- Risk transfer - the solution to the risk in this case is to transfer the risk to a third party or to share it with it. By transferring risk, the investor or organization reduces its exposure to that risk.

- Risk acceptance - dealing with risk's consequences directly. This solution usually develops a plan of action after a risk event has taken place.

\section{Conclusions}

Studying various infrastructure projects, it is concluded that most of them have not met the deadlines and they produce additional costs of construction and modernization. Given that such projects involve large investments, the additional costs can be unpredictably high. The solution to these problems is to improve risk management. It must be present in all phases of the project, from planning to project control after implementation.

The fact that dealing with the uncertainties is an inevitable challenge of every realworld project, makes the using the fuzzy logic appropriate for making decisions in such an unsteady environment.

The Interval Type-2 Fuzzy FMEA is suitable for project risks analysis due to the great potential to solve complex non-linear modeling task. The results of this analysis highlight the most risky events during the construction or modernization of infrastructure railway projects in the Republic of Serbia. Based on the results, a better insight into the possible consequences and measures that need to be taken in order to prevent or correct risk events is provided.

It has been observed that the events with the highest fuzzy RPN number mainly depend on the contractor and infrastructure owner, so they would be considered as responsible persons in these cases. The risk with the highest fuzzy RPN, poor site 
management and QC by the contractor, can be treated by hiring external supervision. Poor communication and coordination of the owner with the designer and / or contractor should be tolerated because such a risk depends on many parties. The risk event of lack of contractor staff on the project can be improved if the right estimates of the required staff are made during the project planning.

In this paper, a model specific to the railways of the Republic of Serbia is developed. However, its application is wide and general, and does not depend on the specifics of the railway system of a country.

Since fuzzy set $[24,25,40]$ was introduced, several extensions have been developed, such as: intutionistic fuzzy set, type-2 fuzzy set, type-n fuzzy set, fuzzy multiset and hesitant fuzzy set. Our future research will be dedicated to the hesitant fuzzy set theory $[23,26,27,28]$ applications for risk analysis regarding the transport infrastructure projects.

The disadvantage of FMEA analysis is reflected in the fact that it looks at individual failure modes rather than theirs combination. Research could evolve by finding ways to combine these elements. Also, it would be better if there were analytical data on risk events over the past few years in order to avoid relying on human assessment of potential risk events. Our future research will include the sensitivity analysis. Sensitivity analysis, as an in-depth study of all the variables, provides a number of benefits for decision-makers and managers in the real-world problems solving.

\section{References}

[1] Panja, S. C., Chakraborty, R., Sarkar, D., Parida, R., Patra, S. Application of Fuzzy FMEA to Indian Railway Signaling Systems. GRD Journals, 2018, pp. 58-63

[2] Zhu, W., Li, Ch., Xiao, X., Xu, W. Diagnosing urban rail transit vehicles with FMEA and fuzzy set. Journal of Quality in Maintenance Engineering, Vol. 21, No. 3, 2015, pp. 332-345

[3] Ghodrati, B., Rahimdel, M. J., Vahed, A. Fuzzy Risk Prioritization of the Failure Modes in Rolling Stocks. IEEE International Conference on Industrial Engineering and Engineering Management (IEEM) 2018, pp. 108112

[4] Huang, W., Zhang, Y. Railway Dangerous Goods Transportation System Risk Assessment: An Approach Combining FMEA With Pessimistic Optimistic Fuzzy Information Axiom Considering Acceptable Risk Coefficient. IEEE Transactions on Reliability, Vol. 70, No. 1, 2021, pp. 371388

[5] Tong, B., Duo, F., Feng, Y., Long, Zh. Research on risk analysis of suspension system in maglev train based on fuzzy multiple attribute decisionmaking. Proceeding of the $11^{\text {th }}$ World Congress on Intelligent Control and Automation, IEEE, 2015, pp. 751-754 
[6] Sarkar, D., Singh, M. Risk analysis by integrated fuzzy expected value method and fuzzy failure mode and effect analysis for an elevated metro rail project of Ahmedabad, India. International Journal of Construction Management, 2020, DOI: 10.1080/15623599.2020.1742634

[7] Tafazzoli, M. Dynamic Risk Analysis of Construction Delays Using Fuzzy - Failure Mode Effects Analysis. Dissertation, University of Nevada, Las Vegas, 2017

[8] Deveci, M., Akyurt, I. Z., Yavuz, S. A GIS-based interval type-2 fuzzy set for public bread factory site selection. Journal of Enterprise Information Management, Vol. 31, No. 6, 2018, pp. 820-847

[9] Turk, S., Deveci, M., Özcan, E., Canitez, F., John, R. Interval type-2 fuzzy sets improved by Simulated Annealing for locating the electric charging stations. Information Sciences, Vol. 547, 2020, pp. 641-666

[10] Deveci, M., Pekaslan, D., Canıtez, F. The assessment of smart city projects using zSlice type-2 fuzzy sets based Interval Agreement Method. Sustainable Cities and Society, Vol. 53, 101889, 2020, 101889

[11] Karagoz, S., Deveci, M., Simic, V., Aydın, N. Interval type-2 Fuzzy ARAS method for recycling facility location problems. Applied Soft Computing, Vol. 102, No. 2, 2021, 107107

[12] Deveci, M., Erdogan, N., Cali, U., Stekli, J., Zhong, Sh. Type-2 neutrosophic number based multi-attributive border approximation area comparison (MABAC) approach for offshore wind farm site selection in USA. Engineering Applications of Artificial Intelligence, 103, 104311, 2021

[13] Fateminia, S. H., Sumati, V., Fayek, A. R. An Interval Type-2 Fuzzy Risk Analysis Model (IT2FRAM) for Determining Construction Project Contingency Reserve. Algorithms, Vol. 13, No. 7, 2020, 163

[14] Fu, Y., Yong, Q., Linlin, K., Xinwang, L., Limin, J. Operational risk assessment of railway train based on type-2 intuitionistic fuzzy set and dynamic VIKOR approach. Journal of Transportation Safety \& Security, 2019, DOI: $10.1080 / 19439962.2019 .1597002$

[15] Kilic, M., Kaya, I. The prioritization of provinces for public grants allocation by a decision-making methodology based on Type-2 Fuzzy sets. Urban Studies, Vol. 53, No. 4, 2015, pp. 755-774

[16] Qin, Y., Zhang, Z., Liu, X., Li, M., Kou, L. Dynamic risk assessment of metro station with interval Type-2 Fuzzy set and TOPSIS method. Journal of Intelligent \& Fuzzy Systems, Vol. 29, No. 1, 2015, pp. 93-106

[17] de Aguiar, P. E., Amaral, R. P. F., Vellasco M. M. B. R., Ribeiro M. V. An enhanced singleton Type-2 Fuzzy logic system for fault classification in a railroad switch machine. Electric Power System Research, Vol. 158, 2018, pp. $195-206$ 
[18] Kumar, S., Jamal, M. A Simple Method for Solving Type-2 and Type-4 Fuzzy Transportation Problems. International Journal of Fuzzy Logic and Intelligent Systems, Vol. 16, No. 4, 2016, pp. 225-237

[19] Maity, S., Kumar Roy, S. A New Approach for Solving Type-2-Fuzzy Transportation Problem. International Journal of Mathematical, Engineering and Management Sciences, Vol. 4, No. 3, 2019, pp. 683-696

[20] Kundu, P., Kar, S., Maiti, M. Multi-item solid transportation problem with Type-2 Fuzzy parameters, Applied Soft Computing, Vol. 31, 2015, pp. 6180

[21] Soner, O., Celik, E., Akyuz, E. Application of AHP and VIKOR methods under interval type 2 fuzzy environment in maritime transportation. Ocean Engineering, Vol. 129, 2017, pp. 107-116

[22] Deveci, M., Canitezb, F., Gokasarc, I. WASPAS and TOPSIS based interval Type-2 Fuzzy MCDM method for a selection of a car sharing station. Sustainable Cities and Society, Vol. 41, 2018, pp. 777-791

[23] Deveci, M., Ozcanb, E., Johnb, R., Oners Sultan, C. Interval type-2 hesitant fuzzy set method for improving the service quality of domestic airlines in Turkey. Journal of Air Transport Management, Vol. 69, 2018b, pp. 83-98

[24] Zadeh, L. A. Fuzzy sets. Inf. Control., Vol. 8, No. 3, 1965, pp. 338-353

[25] Zadeh, L. A. The concept of a linguistic variable and its application to approximate reasoning-II. Inf. Sci., Vol. 8, No. 4, 1975, pp. 301-357

[26] Faizi Sh., Rashid T., Sałabun W., Zafar S., Wątróbski J. Decision Making with Uncertainty Using Hesitant Fuzzy Sets. International Journal of Fuzzy Systems, Vol. 20, 2018, pp. 93-103

[27] Torra, V., Narukawa, Y. On hesitant fuzzy sets and decision. Proceedings of the $18^{\text {th }}$ IEEE International Conference on Fuzzy Systems, Jeju Island, Korea, 2009, pp. 1378-1382

[28] Xu Z. Hesitant Fuzzy Sets Theory. Book in Studies in Fuzziness and Soft Computing, 2014, DOI: 10.1007/978-3-319-04711-9

[29] Blagojević, A., Vesković, S., Kasalica, S., Gojić, A., Allamani, A. The application of the fuzzy AHP and DEA for measuring the efficiency of freight transport railway undertakings. Operational Research in Engineering Sciences: Theory and Applications, Vol. 3, No. 2, 2020, pp. 1-23

[30] Djalic, I., Ateljevic, J., Stevic, Z., Terzic, S. An integrated SWOT - fuzzy Piprecia model for analysis of competitiveness in order to improve logistics performances. Facta Universitatis-Series Mechanical Engineering, Vol. 18, No. 3, 2020, pp. 439-451 
[31] Gharib, M. R. Comparison of robust optimal QFT controller with TFC and MFC controller in a multi-input multi-output system. Reports in Mechanical Engineering, Vol. 1, No. 1, 2020, pp. 151-161

[32] Gorcun, O. F., Senthil, S., Küçükönder, H. Evaluation of tanker vehicle selection using a novel hybrid fuzzy MCDM technique. Decision Making: Applications in Management and Engineering, Vol. 4, No. 2, 2021, pp. 140162

[33] Kazimieras Zavadskas, E., Turskis, Z., Stević, Ž, Mardani, A. Modelling procedure for the selection of steel pipes supplier by applying fuzzy AHP method. Operational Research in Engineering Sciences: Theory and Applications, Vol. 3, No. 2, 2020, pp. 39-53

[34] Malbašić, S. B., Đurić, S. V. Risk assessment framework: Application of Bayesian Belief Networks in an ammunition delaboration project. Military Technical Courier, Vol. 67, No. 3, 2019, pp. 614-641

[35] Milosevic, T., Pamucar, D., Chatterjee, P. Model for selecting a route for the transport of hazardous materials using a fuzzy logic system. Military Technical Courier, Vol. 69, No. 2, 2021, pp. 355-390

[36] Precup, R.-E., Preitl, S., Petriu, E., Bojan-Dragos, C.-A., Szedlak-Stinean, A.-I., Roman, R.-C., Hedrea, E.-L. Model-Based Fuzzy Control Results for Networked Control Systems. Reports in Mechanical Engineering, Vol. 1, No. 1, 2020, pp. 10-25

[37] Vilela, M., Oluyemi, G., Petrovski, A. A holistic approach to assessment of value of information (VOI) with fuzzy data and decision criteria. Decision Making: Applications in Management and Engineering, Vol. 3, No. 2, 2020, pp. $97-118$

[38] Pamucar, D., Ecer, F. Prioritizing the weights of the evaluation criteria under fuzziness: The fuzzy full consistency method - FUCOM-F. Facta Universitatis-Series Mechanical Engineering. Vol. 18, No. 3, 2020, pp. 419437

[39] Milosevic, T., Pamucar, D., Chatterjee, P. Model for selecting a route for the transport of hazardous materials using a fuzzy logic system. Military Technical Courier, Vol. 69, No. 2, 2021, pp. 355-390

[40] Pamucar, D. S., Savin, L. M. Multiple-criteria model for optimal off-road vehicle selection for passenger transportation: BWM-COPRAS model. Military Technical Courier, Vol. 68, No. 1, 2020, pp. 28-64 